\title{
Threshold Cointegration Relationships between Oil and Stock Markets
}

\author{
by \\ Fredj Jawadi \\ and \\ Patrick L. Leoni
}

Discussion Papers on Business and Economics

No. 3/2009

\author{
FURTHER INFORMATION \\ Department of Business and Economics \\ Faculty of Social Sciences \\ University of Southern Denmark \\ Campusvej 55 \\ DK-5230 Odense M \\ Denmark \\ Tel.: +4565503271 \\ Fax: +4565503237 \\ E-mail:1ho@sam.sdu.dk




\title{
Threshold Cointegration Relationships between Oil and Stock Markets
}

\author{
Fredj JAWADI ${ }^{+}$ \\ fredj.jawadi@,supco-amiens.fr \\ (Amiens School of Management and EconomiX -CNRS-University of Paris Ouest Nanterre \\ la Défense, France) \\ Patrick LEONI \\ patrick.1.leoni@gmail.com \\ (University of Southern Denmark, Denmark,)
}

\begin{abstract}
The aim of this paper is to study the oil price adjustment dynamics and to implicitly test the efficiency hypothesis for the oil market. Thus, we propose to study the oil price evolution in a nonlinear framework while testing the interdependence hypothesis between oil and stock markets. Four countries, the USA, France, Mexico and the Philippines are concerned by our findings which show several important results. Firstly, we show some evidence of linear linkage between stock markets and oil industry and we prove the existence of significant long-run relationships between oil and stock markets, indicating that the oil market is not efficient. Secondly, using nonlinear cointegration techniques, we propose a new nonlinear modeling to reproduce the oil price adjustment dynamics. It takes into account both stock and oil market variations. More importantly, the oil price is nonlinear, mean-reverting toward the equilibrium and with an adjustment speed that increases according to oil price deviations toward the stock market equilibrium.
\end{abstract}

JEL: C22, E32, G15.

Keywords: Oil Price Adjustment, Stock Markets, Nonlinear Cointegration.

\footnotetext{
${ }^{+}$Corresponding author : Amiens School of Management, 18 place Saint Michel, 80000 Amiens, France. Tel: + $33(0) 322822441$.
} 


\section{Introduction}

Several studies have taken oil markets as a subject and their number has increased considerably due to the important development of the oil industry, to the increase of the investments and activities depending on oil and energy and to the significant increase of oil price. Indeed, since 2002, New York's monthly average oil price has increased by $483 \%$ and the barrel price has reached an unprecedented level despite the recent deterioration of the US dollar, the slowing of the American economic growth and in spite of the subprime crisis. For instance, the barrel price reached the level of 126.40 US \$ on May, 12, 2008. It has doubled in one year and quadrupled in four years. Thus, the barrel price record of the 1973 and 1979 oil shocks has been broken and the possibility of a $200 \$$ barrel before the end of 2008 still remains before that the recent financial crisis occurs and induces significant decrease of oil market.

The oil price is obviously the result of a perception of the equilibrium between the oil demand and supply. Although this perception is important, a recent sharp increase was caused by other external factors such as the increase of the oil demand from emergent countries like China and India, the multiplication of tensions with Iraq and Iran and the recent interaction between oil and financial markets. In this paper, we shall focus on the latter point.

In the literature, several studies focus on the explanation of oil price evolution (Taylor and Tonk, 1989; Jeon and Chiang, 1991; Masih and Masih, 2000; Chang, 2001; Brown and Yücel, 2002; Anoruo and Mustafa, 2007 among others). However, much of this literature has concentrated on particular hypotheses such as the interaction between the demand and supply of oil and the effect of oil market shocks. When taking into account the possible linkages and interaction between oil and stock markets, these studies have also been less concerned with the explanation of oil price evolution and its dynamic modeling. Moreover, they often examined these linkages using the usual framework of linear modeling. For example, using VECM, Anoruo and Mustafa (2007) find favorable evidence in favor of the cointegration between oil and stock markets. It indicates that investors cannot benefit from diversification while investigating simultaneously in these markets and it also implies that the oil market has accommodated changes in stock prices. Other studies investigated this question extensively in order to check for integration. They established short-term international correlations between the oil and stock markets.

However, according to Kasa (1992), this modeling may be misleading if markets share a common stochastic trend and if investors have a long horizon. The linear cointegration modeling also lost significance because it could not predict the oil price evolution of 1980 and is not able to capture the asymmetry characterizing the oil price dynamics (Lardic and Mignon, 2006; Lardic and Mignon, 2008). Besides, Olsen and Mysen (1994), Brown and Yücel (2002), Lardic and Mignon (2006), Lardic and Mignon (2008) among others show that the linkages between oil price and economic variables are rather asymmetrical. This asymmetry can be associated with the fact that the delay in the aggregate economy which may result from a rise in the oil price is a lot more important than the stimulation which may result from an equivalent fall (Lardic and Mignon, 2008). It is also due to the asymmetry inherent to petroleum product prices and to adjustment costs.

In this paper, we focus on the study of the oil price adjustment hypothesis while taking into account the possible interdependence between oil and stock markets within a nonlinear framework. This enables us to check the efficiency hypothesis for oil markets ${ }^{1}$ and to reproduce the asymmetry and oil price reaction after each stock market correction. The

\footnotetext{
${ }^{1}$ According to Fama (1965), a market is informationally efficient if all available information is instantaneously and completely reflected in the price. Thus, it is not possible to forecast the future price evolution on the basis of the previous price variations because this information is already integrated in the present price.
} 
relationship between oil and stock markets is justified by the fact that a rise in the oil price may imply a rise in the cost production, a slower output growth, a fall of the purchasing power of firms and investors as well as a negative effect on consumption, investment and stock prices.

Therefore, unlike most studies made previously which retained the usual linear cointegration framework, this paper aims at studying the oil price adjustment hypothesis while examining the relationship between oil and stock prices in four countries within a nonlinear framework: two developed countries (the USA and France) and two emergent countries (Mexico and the Philippines) ${ }^{2}$. Formally, we use a particular class of nonlinear cointegration models: The Switching Transition Error Correction models (STECM) that were developed by Van Dijk, Teräsvirta and Franses (2002) among others. For the testing of the nature of oil price adjustment and the reproduction of its reaction toward the stock price, this modeling is more robust than the linear cointegration framework because it enables the adjustment to be asymmetrical and to have a variable convergence speed. As a result, the main empirical contribution of this paper is to highlight that the STECM modeling provides an appropriate approach to test the oil market efficiency hypothesis and reproduce the oil price adjustment dynamics.

This paper will be organized as follows. The next section shall briefly present the STECM modeling. Section 3 will discuss our empirical results and a final section will then conclude this study.

\section{Modeling Nonlinear Adjustment in Oil Prices}

The linear cointegration theory stipulates that although two variables may undergo some short-term disruptions, they may tie a stable relation converging toward a long-term equilibrium (Engle and Granger, 1987). Formally, let $X_{t}$ and $Y_{t}$ be two variables that are not stationary in the level but stationary while differentiating them $d$ times. In the long term, if it is possible to find a linear combination $\mathrm{z}_{\mathrm{t}}$ between these two variables which is stationary, then $X_{t}$ and $Y_{t}$ are linearly cointegrated and the long-run cointegration relationship is given as follows:

$Z_{t}=Y_{t}-a_{0}-a_{1} X_{t}$

Where: $Z_{t}$ is the error-correction term or the residual of the cointegration relationship that measures the variation between $X_{t}$ and $Y_{t} ; a_{0}$ and $a_{1}$ are the estimators of the cointegration relationship.

$X_{t}$ and $Y_{t}$ are integrated of one order (I(1)). They are respectively the stock index and the oil price. Thus, the stationarity of $z_{t}$ indicates the existence of a stable economic relationship between the oil and stock markets and rejects the efficiency hypothesis. Indeed, it implies that it would be possible to expect the evolution of $Y_{t}$ while knowing that of $X_{t}$.

In practice, linear cointegration techniques were used in order to explain the oil price evolution (see Anoruo and Mustafa, 2007 for a recent survey) and its short-term dynamics was checked using the following Linear Error-Correction Model (LECM):

$$
\Delta Y t=\alpha_{0}+\lambda z_{t-1}+\sum_{i=1}^{p} \alpha_{i} \Delta Y_{t-i}+\sum_{j=0}^{p} \beta_{j} \Delta X_{t-j}+\varepsilon_{t}
$$

Where: $\lambda$ is the linear adjustment term that brings back the oil price toward the stock market equilibrium.

\footnotetext{
${ }^{2}$ The first two countries have a central role in the world oil market and are important oil consumers and importers, while the two last have important oil demands.
} 
Nevertheless, this modeling limits the oil price adjustment to be symmetrical, linear and continuous and its adjustment speed to be invariant in time. Moreover, it does not reproduce the asymmetry characterizing oil price fluctuations. To face these limits, we extend this linear modeling to the nonlinear one in order to test the efficiency hypothesis in the long term, not only against linear dependence, but also against any nonlinear alternative.

In such a context, we propose to study the efficiency hypothesis in a nonlinear framework using a threshold cointegration model with two regimes: the STECM. In the first regime, no adjustment occurs and the oil price remains away from the financial market equilibrium most of the time, since its deviations are lower than the adjustment costs. This implies that oil price deviations from the equilibrium last for a very long time, that they can be divergent and have a unit root, even though they do not necessarily follow a random walk. In the second regime, the oil price adjustment is rather active, its speed depends on the size of the price disequilibrium and the oil price deviations approach a white noise. Overall, the oil price deviations follow a nonlinear process that is mean-reverting with a convergence speed varying directly with the size of oil price deviations from the equilibrium.

Threshold cointegration models were introduced by Balke and Fomby (1997) and developed by Anderson (1997) who proposed an extension to these models that takes into account gradual transitions rather than abrupt ones, thus defining the STECM. The STECM modeling was developed more recently by Van Dijk et al. (2002). These models were particularly used to reproduce the financial asset adjustment dynamics toward the equilibrium (Anderson, 1997; Van Dijk et al. 2002; Prat and Jawadi, 2008).

More particularly, the exponential STECM defines different regimes and specifies the oil price adjustment in each regime according to the strengths exercised by financial markets. The adjustment takes place in every period, but with an adjustment speed that varies with the size of oil price deviations. In the first regime, the oil price is notably governed by its previous dynamics, but when its deviations $\left(\mathrm{z}_{\mathrm{t}}\right)$ exceed some threshold, the adjustment will be active and the oil price will be mean-reverting toward the equilibrium.

Formally, the exponential STECM is defined as follows:

$\Delta Y_{t}=\alpha_{0}+\lambda_{1} z_{t-1}+\sum_{i=1}^{p} \alpha_{i} \Delta Y_{t-i}+\sum_{j=0}^{p} \beta_{j} \Delta X_{t-j}+\lambda_{2} z_{t-1} \times F\left(\gamma, c, z_{t-d}\right)+\varepsilon_{t}$

Where: $\mathrm{F}\left(\gamma, \mathrm{c}, \mathrm{z}_{\mathrm{t}-\mathrm{d}}\right)=1-\exp \left[-\gamma\left(\mathrm{z}_{\mathrm{t}-\mathrm{d}}-\mathrm{c}\right)^{2}\right], \gamma>0$ and $\mathrm{c}$ are respectively the transition speed and the threshold parameter, $\mathrm{z}_{\mathrm{t}-\mathrm{d}}$ is the transition variable, $\mathrm{z}_{\mathrm{t}}$ is the error-correction term of the linear cointegration relationship (equation (1)) and $\varepsilon_{t} \rightarrow \mathrm{N}\left(0, \sigma^{2}\right)$.

This modeling describes two dynamics corresponding to the extreme values of $F(0$ and 1) and an intermediate state continuum when $F$ takes a value between 0 and 1 . The central regime is defined when the oil price adjustment dynamics is close to the equilibrium and corresponds to:

$$
\Delta Y_{t}=\alpha_{0}+\lambda_{1} z_{t-1}+\sum_{i=1}^{p} \alpha_{i} \Delta Y_{t-i}+\sum_{j=0}^{p} \beta_{j} \Delta X_{t-j}+\varepsilon_{t}
$$

The extreme regimes are defined as follows:

$$
\Delta Y_{t}=\alpha_{0}+\left(\lambda_{1}+\lambda_{2}\right) z_{t-1}+\sum_{i=1}^{p} \alpha_{i} \Delta Y_{t-i}+\sum_{j=0}^{p} \beta_{j} \Delta X_{t-j}+\varepsilon_{t}
$$

$\lambda_{1}$ and $\lambda_{2}$ are the most important parameters that specify the oil price adjustment dynamics and define its convergence speed toward the equilibrium. Indeed, even though $\lambda_{1}$ is positive, $\lambda_{2}$ and $\left(\lambda_{1}+\lambda_{2}\right)$ have to be negative and statistically significant in order to validate a nonlinear oil price mean-reverting process. This implies that for a small disequilibrium, the oil price deviations would diverge from the equilibrium and would be characterized by a unit root 
or an explosive behavior, but for important deviations, the adjustment process would be mean-reverting,

The implementation steps of the STECM are rigorously described in Van Dijk et al.(2002). They are similar to those of the Smooth Transition Autoregressive Models (STAR) of Granger and Teräsvirta (1993) and Teräsvirta (1994).

In practice, according to Van Dijk et al. (2002), we first check the linear cointegration hypothesis as in Engle and Granger (1987). Secondly, we test the linearity hypothesis. Finally, while rejecting the linearity hypothesis, we estimate the STECM by the Nonlinear Least Squares (NLS).

\section{Empirical Analysis}

\section{3-1 Data}

Monthly data were used for the period December, 1987 - March, 2008 concerning France, the United States of America, Mexico and the Philippines. The stock indexes come from Morgan Stanley Capital International (MSCI) while the oil price series were obtained from the Dow Jones \& Company database. Stock indexes are closing prices and the observation number is sufficient to apply the linearity tests. All data are converted in US dollars in order to avoid the change risk and they are also transformed in logarithm to reduce their variance.

\section{3-2 Linear Cointegration Tests}

We need to establish the stationarity of $z_{t}$ in order to test the hypothesis of linear cointegration between the oil price and stock index for the above countries. The stationarity of zt implies that oil and stock prices are at least linearly cointegrated and that both markets are interdependent and integrated.

Following the two-stage procedure of Engle and Granger (1987), we begin by testing the stationarity hypothesis for all studied series. Applying two tests, the ADF tests of Dickey and Fuller (1981) and the test of Phillips and Perron (1988), we prove that that all series are not stationary in level but stationary in the first difference, indicating that they are $\mathrm{I}(1)^{3}$. Secondly, we estimate the long-run relationship (equation (1)) and test the null hypothesis of non-cointegration and the results are then reported in table 1. According to the ADF test, our findings don't reject the hypothesis of linear cointegration for all the countries studied either at $5 \%$ or $10 \%$, implying that oil and stock markets are at least linearly linked and concluding on the rejection of the efficiency hypothesis of the oil market. This result is in line with that of Lardic and Mignon (2008) who also suggested significant linkages and asymmetrical cointegration relationship between oil prices and GDP.

\footnotetext{
${ }^{3}$ The results of unit root tests are given upon request to the authors.
} 
Table 1

Linear Cointegration Test

\begin{tabular}{|l|l|l|l|l|}
\hline & France & USA & Mexico & Philippines \\
\hline $\mathrm{a}_{0}$ & -1.25 & 0.092 & 0.52 & 4.3 \\
& $(-4.33)$ & $(0.31)$ & $(2.83)$ & $(15.2)$ \\
\hline $\mathrm{a}_{1}$ & 0.66 & 0.49 & 0.38 & -0.19 \\
& $(15.6)$ & $(10.8)$ & $(14.9)$ & $(-3.69)$ \\
\hline $\mathrm{R}^{2}$ & 0.50 & 0.32 & 0.48 & 0.05 \\
\hline ADF & $-4.11^{*}$ & $-3.16^{*}$ & $-4.13^{*}$ & $-3.25^{*}$ \\
\hline
\end{tabular}

Note: Values between brackets are the t-ratio.

This result implies that oil and stock prices are linearly mean reverting. However, this result has to be carefully analyzed since ADF tests are not powerful enough for series that are generated by nonlinear processes, as Taylor et al. (2001), among others, pointed out. Besides, these tests are based on linear specification (equation (2)) that may not reproduce the possible asymmetry and nonlinearity characterizing oil price dynamics. According to Van Dijk et al. (2002), we propose to extend our study to the nonlinear framework. Thus, we test the nonlinear adjustment hypothesis in order to check the efficiency assumption while applying nonlinear adjustment tests that are more powerful than the usual linear cointegration tests.

\section{3-3 Nonlinear Adjustment Tests}

Before applying the linearity tests, we check the statistical properties of the oil return and test the normality hypothesis (table 2). The symmetry and normality hypotheses are statistically and significantly rejected, which may be associated with a possible nonlinearity characterizing the dynamics of oil returns.

Table 2

Descriptive Statistics of Oil returns

\begin{tabular}{|l|l|l|l|l|l|}
\hline & Mean & $\begin{array}{l}\text { Standard } \\
\text { deviation }\end{array}$ & Skewness & Kurtosis & JB \\
\hline Oil returns & 0.0075 & 0.077 & -0.281 & 4.66 & 31.01 \\
\hline
\end{tabular}

Note: JB designates the statistics of the Jarque-Bera test.

To check this, we apply the nonlinear adjustment tests that were developed by Luukkonen and Saïkkonen (1988) and also clearly discussed in Teräsvirta (1994) and Van Dijk et al. (2002). The main idea of these tests is to test the null hypothesis of linearity (equation (2)) against its nonlinear alternative (equation (3)).

Thus, in practice, we first specify the LECM and we determine its lag number using the Information Criteria (AIC, Shwarz), the tests of Ljung-Box (1978) and the autocorrelation function. Empirically, these specification tests retain $\mathrm{p}=1$ as optimal lag for all studied countries. 
In a second step, we test the linearity hypothesis by testing the null hypothesis of the LECM against its ESTECM counterpart. According to Teräsvirta (1994) and Van Dijk et al. (2002), the linearity hypothesis is tested for several values of $\mathrm{d}^{4}$. As we use monthly data and suppose a maximal dependence of six months, we consider $d \in[1,2,3,4,5,6]$ as plausible values of the delay parameter $(\mathrm{d})$.

Table 3

\section{Linearity Tests (p-values)}

\begin{tabular}{|c|c|c|c|c|c|}
\hline $\mathbf{d}$ & $\begin{array}{c}\text { LM } \\
\text { Statistics }\end{array}$ & France & USA & Mexico & Philippines \\
\hline $\mathrm{d}=1$ & $\mathrm{LM}_{2}$ & $0.04^{*}$ & $0.01^{*}$ & 0.16 & $0.07^{*}$ \\
& $\mathrm{LM}_{4}$ & 0.03 & 0.03 & 0.19 & 0.10 \\
\hline $\mathrm{d}^{*}=2$ & $\mathrm{LM}_{2}$ & 0.04 & 0.09 & 0.05 & 0.09 \\
& $\mathrm{LM}_{4}$ & 0.09 & 0.13 & 0.11 & 0.13 \\
\hline $\mathrm{d}=3$ & $\mathrm{LM}_{2}$ & 0.14 & 0.06 & 0.10 & 0.10 \\
& $\mathrm{LM}_{4}$ & 0.07 & 0.13 & 0.06 & 0.23 \\
\hline $\mathrm{d}=4$ & $\mathrm{LM}_{2}$ & 0.23 & 0.12 & 0.09 & 0.12 \\
& $\mathrm{LM}_{4}$ & 0.11 & 0.08 & 0.13 & 0.33 \\
\hline $\mathrm{d}=5$ & $\mathrm{LM}_{2}$ & 0.12 & 0.21 & 0.22 & 0.32 \\
& $\mathrm{LM}_{4}$ & 0.13 & 0.33 & 0.23 & 0.63 \\
\hline $\mathrm{d}=6$ & $\mathrm{LM}_{2}$ & 0.22 & 0.32 & 0.02 & 0.42 \\
& $\mathrm{LM}_{4}$ & 0.31 & 0.43 & 0.08 & 0.53 \\
\hline
\end{tabular}

Note: $(*)$ designates the optimal value for which the linearity is strongly rejected.

Among several linearity tests, we apply Lagrange Multiplier tests which follow a standard $\chi^{2}$ under $\mathrm{H}_{0}$. More particularly, we apply two tests $-L M_{2}$ and $L M_{4}$ - that are respectively distributed as $\chi^{2}(2(p+1))$ and $\chi^{2}(4(p+1))$. In Table 3 we notice that the application of these tests proves that the linearity is rejected for several plausible values of $d$. This rejection is even stronger for $d=1$ for France, the USA and the Philippines and for $d=6$ for Mexico. $\mathrm{z}_{\mathrm{t}-6}$ is then retained as the transition variable for Mexico and $\mathrm{z}_{\mathrm{t}-1}$ as the transition variable for France, the USA and the Philippines.

This implies that the oil price adjustment is nonlinear and that its dynamics is nonlinearly mean-reverting toward the equilibrium of the stock markets of these studied countries. Overall, the rejection of linear adjustment hypothesis implies a rejection of the hypothesis according to which the adjustment is symmetrical, linear and with constant speed. It also indicates that the observed oil price deviation is not necessarily a constant that is proportional to the deviation observed in the preceding period. Moreover, the acceptation of nonlinearity indicates evidence of an asymmetric cointegration relationship between oil and stock prices, meaning that the linkages between these markets are strongly activated only when prices are highly increasing or decreasing, thus enabling a variable adjustment speed. This result is also in line with that of Lardic and Mignon (2008) who give evidence in favor of the asymmetrical cointegration between oil prices and GDP.

In a last step, we use the ESTECM to specify the nonlinear modeling characterizing the oil price adjustment dynamics.

\section{3-4 Nonlinear Estimation Results}

As in Michael et al. (1997) and Van Dijk et al. (2002), we first estimate the LECM using the OLS method to initialize the ESTECM parameters. Secondly, we estimate the ESTECM. The parameters of the exponential function $\gamma$ and $\mathrm{c}$ are also initialized by trying

\footnotetext{
${ }^{4} \mathrm{~d}$ is the delay parameter that defines the transition variable.
} 
various starting values. Our empirical results show several important findings notably in the American, French and Mexican cases. Firstly, most estimators are statistically significant for France, Mexico and the USA and show a strong evidence of nonlinear relationship between stock and oil markets, indicating the the latter are not informationally efficient. More particularly, the current and lagged stock returns affect the oil market short-term adjustment dynamics negatively and significantly, implying that both markets are a priori integrated. Secondly, even though the estimation transition speed is relatively high for the three abovementioned countries, $\hat{\gamma}$ and $\hat{c}$ are statistically significant confirming the choice of the exponential function.

Thirdly, the major parameters of the $\operatorname{ESTECM}\left(\lambda_{1}\right.$ and $\left.\lambda_{2}\right)$ have the appropriate sign. The adjustment term in the first regime $\lambda_{1}$ is positive and/or not significant, except for the Philippines, implying that the oil price could deviate from the stock price equilibrium and stay away from it for a long period. However, the adjustment term in the second regime $\lambda_{2}$ is rather negative and strongly significant indicating that for large deviations the oil price would be nonlinearly mean-reverting. Moreover, the sum $\left(\lambda_{1}+\lambda_{2}\right)$ is negative, thus confirming a nonlinear mean-reversion in the oil price for France, the USA and Mexico ${ }^{5}$ and indicating that the oil price reacts asymmetrically to stock price shocks (see Lardic and Mignon (2008) for a brief survey on the sources of this asymmetric relationship). What is also important to note is that our findings confirm the presence of two regimes characterizing the oil price dynamics: a "pure chartist regime" according to which the oil price adjustment is essentially governed by its previous tendencies and a "stock market follower regime" according to which the adjustment is more activated and according to which integration between oil and stock markets is statistically very strong.

\section{Table 4}

ESTECM Estimation Results

\begin{tabular}{|l|l|l|l|l|}
\hline Coefficients & France & USA & Mexico & Philippines \\
\hline Model & ESTECM (1,1) & ESTECM (1,1) & ESTECM (1,6) & ESTECM (1,1) \\
\hline $\boldsymbol{\alpha}_{\mathbf{0}}$ & $0.012^{*}$ & 0.008 & 0.008 & -0.008 \\
& $(2.2)$ & $(1.57)$ & $(1.47)$ & $(-0.54)$ \\
\hline$\lambda_{\mathbf{1}}$ & 0.25 & 0.18 & $-0.18^{* *}$ & $-0.09^{*}$ \\
& $(1.42)$ & $(1.61)$ & $(-1.84)$ & $(-2 . .4)$ \\
\hline $\boldsymbol{\alpha}_{\mathbf{1}}$ & $0.22^{*}$ & $0.20^{*}$ & $0.24^{*}$ & $0.23^{*}$ \\
& $(3.4)$ & $(2.92)$ & $(3.6)$ & $(3.3)$ \\
\hline $\boldsymbol{\beta}_{\mathbf{0}}$ & $-0.19^{* *}$ & $-0.38^{*}$ & - & $-0.1^{* *}$ \\
& $(-1.94)$ & $(-3.12)$ & $-1.82)$ \\
\hline $\boldsymbol{\beta}_{\mathbf{1}}$ & - & $-0.21^{* *}$ & - & - \\
& & $(-1.67)$ & & $0.11^{*}$ \\
\hline $\boldsymbol{\lambda}_{\mathbf{2}}$ & $-0.28^{*}$ & $-0.20^{*}$ & $-0.17^{* *}$ & $(2.7)$ \\
\hline $\boldsymbol{\gamma}$ & $(-2.57)$ & $(-1.99)$ & $(-1.72)$ & 1.06 \\
& $17.97^{*}$ & $79.63^{*}$ & $60.9^{* *}$ & $(0.78)$ \\
\hline $\mathbf{C}^{*}$ & $(2.52)$ & $(2.75)$ & $(1.64)$ & $-0.50^{*}$ \\
& $-0.11^{* *}$ & $0.40^{*}$ & $0.08^{*}$ & $(-3.54)$ \\
\hline ADF & $(-1.83)$ & $(18.58)$ & $(3.4)$ & -11.3 \\
\hline ARCH & -11.08 & -10.07 & -11.05 & 0.18 \\
\hline JB $^{\mathbf{b}}$ & 0.11 & 0.51 & 0.23 & 0.47 \\
\hline
\end{tabular}

Note: $\left(^{*}\right)$ and (**) designate respectively the statistical significance at $5 \%$ and $10 \%$. (a) and (b) designate respectively the p-values of the ARCH and normality tests. Values between brackets are the t-ratio.

\footnotetext{
${ }^{5}$ Our modeling did not give "good" results for the Philippines. For the other countries, the results are rather appropriate. The misspecification tests show that their residuals are stationary, homoscedastic and normal.
} 
To represent these regimes more explicitly, we plot the estimated transition function in function of the transition variable (graphic 1) ${ }^{6}$ which enables us to explain the oil price behavior in each regime and to determine its reaction and adjustment speed after each stock market correction.

\section{Graphic 1:}

\section{France}

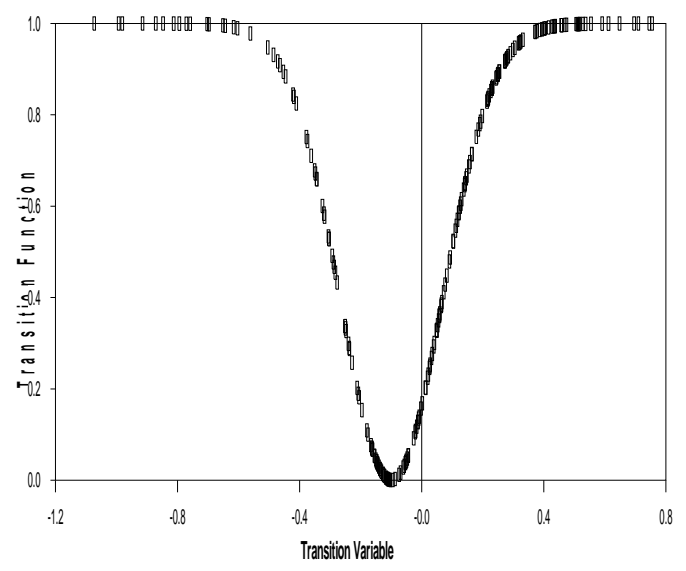

The Philippines

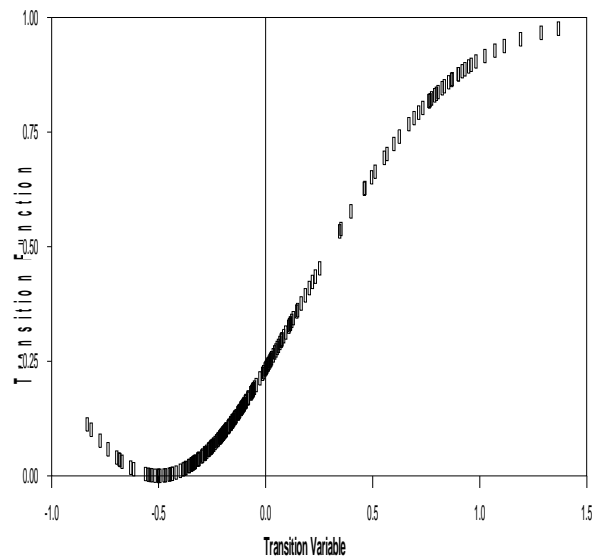

\section{The USA}

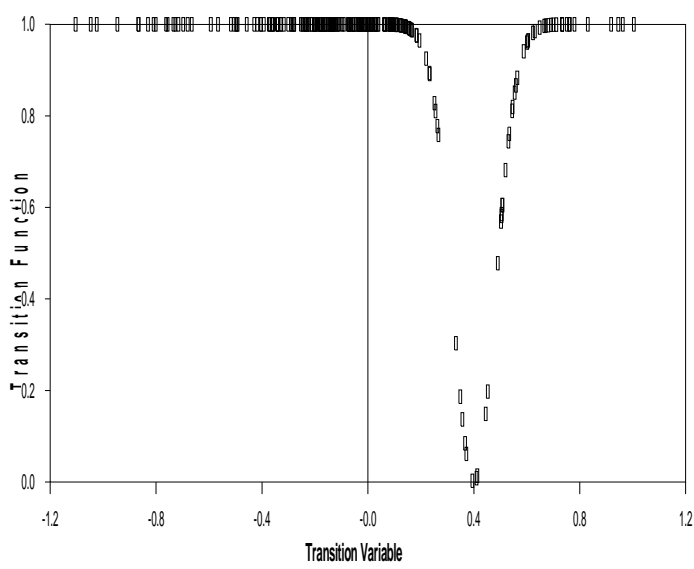

Mexico

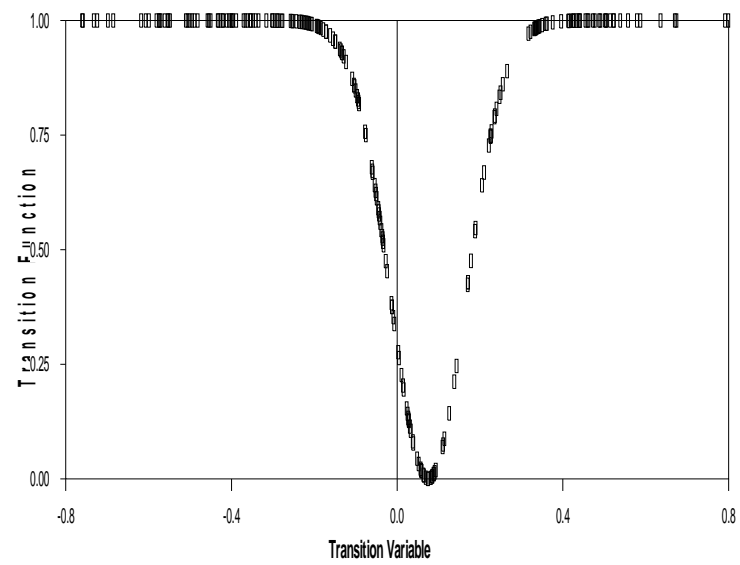

The analysis of these representations shows that the estimated transition function for the Philippines is rather similar to a logistic function, whereas an exponential function seems to be more appropriate to the USA, France and Mexico. For the latter, our representation clearly distinguishes a central regime and two upper regimes. In the central regime, the oil price deviations are lower, the adjustment is absent and the price can deviate from the equilibrium. Oil price deviations are close to the unit root in this zone. However, in the upper regimes, when deviations become more important, the adjustment is activated and its convergence speed increases according to the size of oil price deviations. This also confirms that the oil price reacts asymmetrically to any stock market correction or shock.

In other respects the transition function approaches unity and remains in the upper regime, indicating that the oil price adjustment for France, the USA and Mexico is activated for a long period and that it is nonlinearly mean-reverting with a an adjustment speed that increases with the size of the deviation from equilibrium. Indeed, the oil price may undergo

\footnotetext{
${ }^{6}$ To our knowledge, no previous study has ever presented the transition function for the oil price.
} 
some short-term disruptions, but it nevertheless shares some similarities with the stock market's properties in the long term. The oil price and stock market may thus tie steady relations which converge toward an equilibrium for which the adjustment dynamic is nonlinear.

\section{Conclusion}

In this paper, we check the oil market efficiency hypothesis in a nonlinear framework, while studying the oil price adjustment dynamics and testing the impact of stock market on oil price dynamics. Our findings reject the informational efficiency hypothesis and show strong evidence of a significant nonlinear cointegration relationship between the oil and stock markets for France, the USA and Mexico. The ESTECM modeling is appropriate to the reproduction of the oil price adjustment dynamics. Another important empirical finding concerns the specification of two distinct oil price regimes: a "pure chartist regime" for which the oil price adjustment is determined by its previous tendencies and a "stock market follower regime" for which the adjustment is more activated.

More interestingly, the oil price is nonlinearly mean-reverting toward the stock market equilibrium with an adjustment speed that increases according to the size of the disequilibrium. These results may also explain the alternation of stock and oil crises and the "co-movements" between oil and of stock prices. To take this research further, it would be interesting to extend this study to another important group of developed and emergent countries and to apply these nonlinear modeling techniques to a multivariate framework.

\section{References}

Anderson, H.M., 1997, Transaction Costs and Nonlinear Adjustment Toward Equilibrium in The US Treasury Bill Markets, Oxford Bulletin of Economics and Statistics 59, 465-484.

Anoruo, E., Mustafa, M., 2007. An Empirical Investigation Into the Relation of Oil to Stock Market Prices. North American Journal of Finance and Banking Research 1, n 1, 22-36.

Balke, N.S., Fomby T.B., 1997, Threshold Cointegration, International Economic Review 38, 627-646.

Brown, S.P.A., Yücel, M.K., 2002. Energy Prices and Aggregate Economic Activity. Federal Reserve Bank of Dallas Economic Review 16-53.

Chang, T., 2001. Are there any long-run benefits from International Equity Diversification for Taiwan Investors Diversifying in the Equity Markets of Its Major Trading Partners, Hong Kong, Japan, South Korea, Thailand and the USA? Applied Economics Letter 8, 441-446.

Dickey, D.A., Fuller, W.A., 1981, Likelihood Ratio Statistics for Autoregressive Time Series With a Unit Root, Econometrica 49, 1057-1072.

Engle, R.F., Granger, C.W.J., 1987, Cointegration and Error Correction: Representation, Estimation and Testing, Econometrica 55, 2, 251-276.

Fama, E.F., 1965, The Behavior of Stock Market Prices. Journal of Business 38, n 1, 31-105. Granger, C.W.J., Teräsvirta, T., 1993. Modeling Nonlinear Economic Relationships, Oxford University Press.

Jeon, B., Chiang, T. 1991. A System of Stock Prices in World Stock Exchanges: Common Stochastic trends for 1975-1990? Journal of Economics and Business 43, 329-338.

Lardic, S., Mignon, V., 2006, The Impact of Oil Prices on GDP in European Countries: An Empirical Investigation based on Asymmetric Cointegration. Energy Policy 34, 3910-3915.

Lardic, S., Mignon, V., 2008, Oil Prices and Economic Activity: An Asymmetric Cointegration Approach. Energy Economics 30, 847-855. 
Ljung, G., Box, G.E., 1978, On a Measure of Lack of Fit in Time Series Models, Biometrika 65, 297-303.

Luukkonen, R., Saïkkonen, P., 1988, Lagrange Multiplier Tests for Testing Nonlinearity in Time Series Models, Scandinavian Journal of Statistic 15, 65-68.

Masih, A., Masih, R., 1997. Dynamic Linkages and the Propagation Mechanism Driving Major International Stock Markets: An Analysis of Pre-and Post-Crash Eras. Quarterly Review of Economics and Finance 37, 859-885.

Michael P., Nobay, A.R., Peel, D.A., 1997, Transactions Costs and Nonlinear Adjustment in the Real Exchange Rates: An Empirical Investigation. Journal of Political Economy 105, 862879.

Phillips, P.C.B., Perron P., 1988, Testing for Unit Root in a Time Series Regression, Biometrika 75, 335-346.

Prat, G., Jawadi, F., 2008, Nonlinear Stock Price Adjustment in the G7 Countries. Working Paper, University of Paris Ouest La Defense Nanterre.

Taylor, M., Tonk, I., 1989. The Internationalization of Stock Markets and the Abolition of UK Exchange Control. Review of Economics and Statistics 71, 332-336.

Taylor, M.P., Peel, D.A., Sarno, L. 2001, Nonlinear Mean-Reversion in Real Exchange Rates: Towards a Solution to the Purchasing Power Parity Puzzles. International Economic Review 4, 1015-1041.

Teräsvirta, T., 1994. Specification, Estimation and Evaluation of Smooth Transition Autoregressive Models. Journal of the American Statistical Association 89, 208-218.

Van Dijk D., Teräsvirta T., Franses P.H., 2002. Smooth Transition Autoregressive Models- A Survey of Recent Developments, Econometric Reviews 21, 1-47. 